\title{
Erratum to: Climate Change Adaptation: Putting Principles into Practice
}

\author{
Malcolm Ausden
}

Published online: 21 January 2014

(C) Springer Science+Business Media New York 2014

\section{Erratum to: Environmental Management DOI 10.1007/s00267-013-0217-3}

The following errors were inadvertently overlooked in the original publication and they have been corrected with this erratum.

1) Unfortunately, the word "predicted" was missing from the sixth sentence of the "Abstract" section.

The correct sentence should read:

"Significant predicted long-term impacts of climate change most frequently identified at RSPB reserves are: loss of intertidal habitat through coastal squeeze, loss of low-lying islands due to higher sea levels and coastal erosion, loss of coastal freshwater and brackish wetlands due to increased coastal flooding, and changes in the hydrology of wetlands."

2) In the section "Climate Change Adaptation Measures on the RSPB's Nature Reserves," the second sentence in the second paragraph reads incorrectly.

The correct text should read:

"It also includes a range of other actions that are expected to facilitate adaptation of wildlife to climate change, but there are many more measures carried out as best practices for conservation, which are not included."

The online version of the original article can be found under doi: 10.1007/s00267-013-0217-3.

M. Ausden $(\bowtie)$

RSPB, The Lodge, Sandy, Bedfordshire SG19 2DL, UK

e-mail: malcolm.ausden@rspb.org.uk 